\title{
REMOVAL OF E.Coli FROM GROUNDWATER AND SURFACE WATER BY USING NYLON MEMBRANE FILTRATION TECHNIQUE
}

\author{
S. Vanitha, P. Vijayalakshmi*, P.K. Raji and M. Praba \\ Department of Civil Engineering, Sathyabama Institute of Science and Technology, \\ Chennai-600119, (Tamilnadu) India \\ *E-mail: vijayalakshmipanneerselvam@yahoo.co.in
}

ABSTRACT

In the present study, a low-cost filter material such as Nylon was used for the disinfection of groundwater poses an excellent bacterial filtration activity against Escherichia coli (gram-negative) cultures. Textile fabrics have gained wide acceptance as a filtration membrane, and various substrates having a pore size in microns such as Nylon, polyester, and cotton have been shown to develop microbial filtration properties. In this study, a simple method to filter bacteria using nylon is presented and the solutions are prepared using Autoclave and Laminar Air Flow Chamber. For checking the bacterial concentration in the underground water, a very small volume of sample was tested by keeping it in shaking Incubator. The results revealed that nylon filters were able to decrease the concentration of $E$. coli from a groundwater sample, with a higher removal efficiency achieved by using two membranes and a lower efficiency by using a single membrane. This study, therefore, suggests that the Nylon membrane demonstrated antibacterial activity against E.Coli. For the disinfection of groundwater, Nylon membrane can be used as a potential alternative cost-effective filter for production of safe drinking water.

Keywords: E.Coli, Nylon membrane, groundwater, surface water, bacteria

(C) RASĀYAN. All rights reserved

\section{INTRODUCTION}

In developing countries, waterborne diseases have a negative impact on public health where the drinking water is of a poor quality ${ }^{1}$.Escherichia coli are present in large numbers in the normal intestinal flora of humans and animals, where it generally causes no harm. However, in other parts of the body, E. coli can cause serious diseases, such as urinary tract infections, bacteremia and meningitis ${ }^{2}$.The silverimpregnated porous pot filter (SIPP) can be recommended for use by rural communities as it consistently produced high-quality water that complied with the SANS 241 turbidity and microbiological limits for drinking water ${ }^{3}$.Various point-of-use (POU) water treatment methods, which include bio-sand and ceramic filtration, appropriate chemical disinfection (e.g. the use of disinfectants such as chlorine and iodine), solar disinfection and natural water purifiers (e.g. Moringa oleifera) have been reported to improve the microbial quality of drinking water as well as to decrease the incidence of endemic diarrhoea caused by waterborne pathogens ${ }^{4}$.The source of the microorganism was traced to the park's water supply, which had been contaminated with raw sewage and Enterotoxigenic E.coli was identified as the microorganism responsible for this outbreak ${ }^{5}$. The functionalized nano fiber structures have an effect on bacterial growth was confirmed by microbiological, physic-chemical and molecular biological analyses, such as the inoculation in a nutrient agar culture medium, flow cytometry, and real-time polymerase chain reaction ${ }^{6}$.

The silver-impregnated porous pot (SIPP) can be an effective and sustainable household water treatment devices/systems (HWTS) for the Southern African Development Community (SADC) rural communities, in the removal of the total concentration of bacteria from test water, manufactured using locally available materials, easy to operate and to maintain ${ }^{7}$.

Rasayan J. Chem., 12(1), 32-39(2019)

http://dx.doi.org/10.31788/RJC.2019.1215041 
RASĀYAN J. Chem.

Vol. 12 | No. 1 |32 - 39| January - March | 2019

Decentralized point-of-use (POU) systems are possible short-term to medium-term options for improving water quality for rural communities and could be very beneficial to individuals or families who treat their own water ${ }^{8}$.

Waterborne pathogens and related diseases are a major public health concern worldwide 9 . Water purification easier for the rural community, by different techniques and methods involving naturally available resources such as sand, carbon, soil, bricks and so on ${ }^{10}$.Contamination of water by foreign matter such as micro-organisms, chemicals, and industrial or other wastes, or sewage are water pollution $^{11}$. One of the Nation's most important natural resources is groundwater and an important source of water supply for drinking, irrigation, and industrial purposes ${ }^{12}$. Causes greater deterioration of the ecological system is because of pollution level acceleration ${ }^{13}$.

Higher the number of fecal coliforms and fecal streptococci indicates the greater is the possibility of the presence of pathogenic micro-organisms and live in the gastrointestinal tract of humans and warmblooded animals such as Escherichia coli, Salmonella, Shigella, Vibriones, and Hepatitis A and D. ${ }^{14}$

The proven antibacterial activity of synthesized copper nanoparticles against Escherichia coli established and capable of rendering high antibacterial efficacy and hence has a great potential in the preparation of drugs used against bacterial diseases. ${ }^{15}$

\section{EXPERIMENTAL}

All the chemicals were purchased from Delta Laboratories Pt. Ltd. and the Nylon membrane was purchased from PALL Corporation (Life Sciences). The Ingredients of different chemicals are tabulated Table-1.

Table -1: Illustrate the ingredients used in the preparation of E.coli

\begin{tabular}{c|c|c|c}
\hline \multicolumn{2}{c|}{ Nutrient Agar } & \multicolumn{2}{c}{ Luria Bertani Broth } \\
\hline Ingredients & Quantity $(\mathrm{gm} / \mathrm{L})$ & Ingredients & Quantity $(\mathrm{gm} / \mathrm{L})$ \\
\hline Beef extract & 3.0 & Yeast extract & 5.0 \\
\hline Peptic digest of animal tissues & 5.0 & Casein enzymic hydrolysates & 10.0 \\
\hline Agar & 15.0 & Sodium chloride & 5.0 \\
\hline Final pH(at $250 \mathrm{C})$ & $6.8 \pm 0.2$ & Final $\mathrm{pH}\left(\right.$ at $\left.25^{\circ} \mathrm{C}\right)$ & $7.0 \pm 0.2$ \\
\hline
\end{tabular}

Luria Bertani Broath, Nutrient Agar, Distilled Water, Agar-Agar type-I, Cotton plug; Micropipette, Ethanol, Loop, etc. were used as per the requirement. Underground Water and E.Coli culture were used accordingly. Specifications of the materials used are Plastic Petri dish (9 $\mathrm{cm}$ dia.), conical flask (250 $\mathrm{ml})$, and Test tube $(10 \mathrm{ml})$, Micropipette Tips (1 ml), Nylon 6, 6 Membrane (0.45 micron) (Fig.- 2).

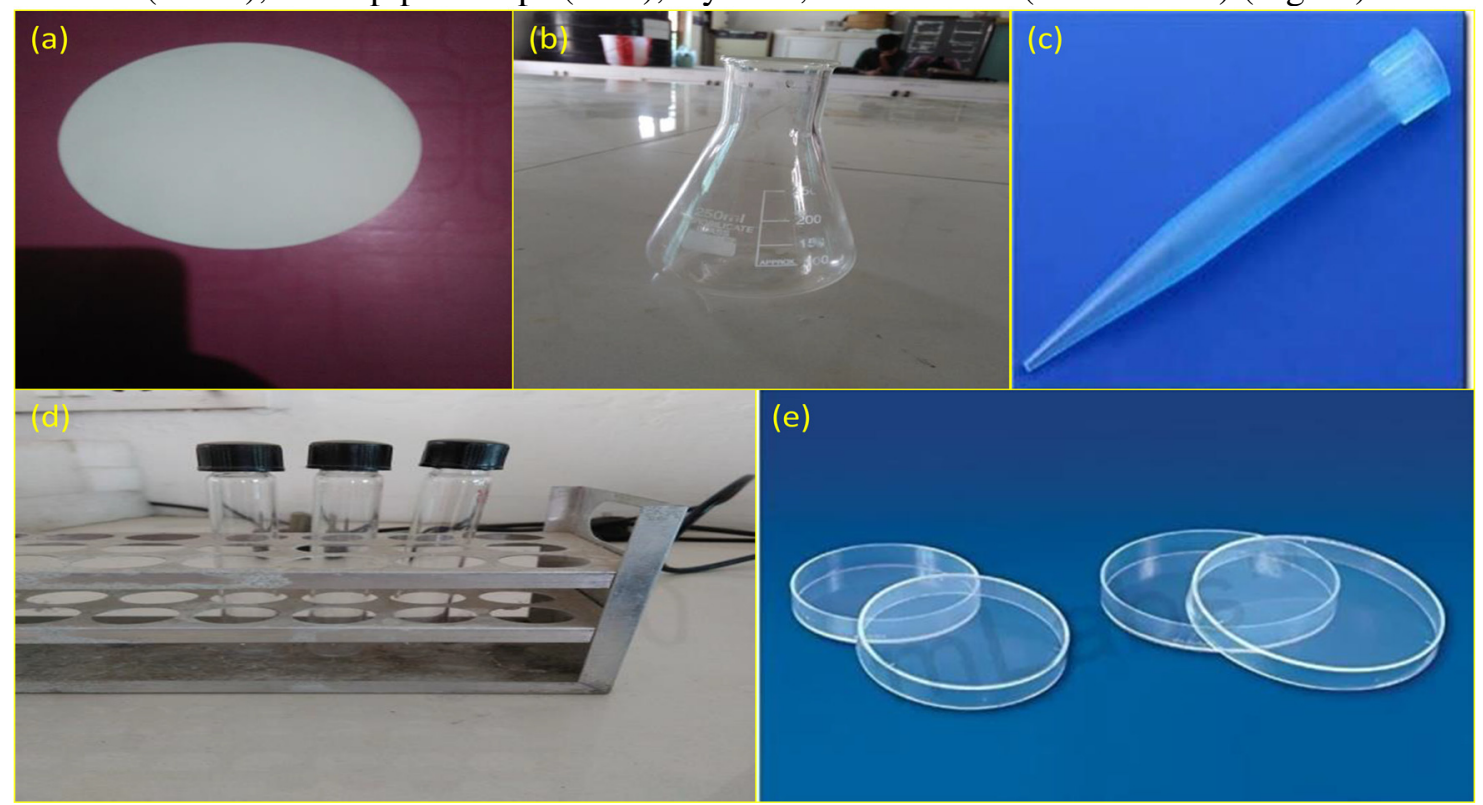

Fig.-1: Plastic Petri dish (9 cm dia.), conical flask $(250 \mathrm{ml})$, and Test tube $(10 \mathrm{ml})$,Micropipette Tips $(1 \mathrm{ml})$, Nylon 6, 6 Membrane (0.45 micron). 


\section{Plate Dish}

Figure-1 shows the details of a plastic Petri dish (9 cm dia.), conical flask $(250 \mathrm{ml})$, and test tube $(10 \mathrm{ml})$, micropipette Tips $(1 \mathrm{ml})$, nylon 6, 6 membranes $(0.45$ micron). Petri dishes are used to culture cells such as bacteria or small mosses. And it is reused after sterilization (via an autoclave at $121{ }^{\circ} \mathrm{C}$ for about $15-20$ minutes in the case of moist heat sterilization or one hour's dry-heating in a hot-air oven at $160{ }^{\circ} \mathrm{C}$.

\section{Nylon 6, 6 Membranes}

The separation of microorganisms has been done using the pressure-driven membrane processes. In this paper, the preparation and characterization of a novel nylon 6,6 nanofibres membranes and applied it for filtration of Chlorella vulgaris broth. Phase inverted polyvinylidene fluoride (PVDF) membrane is used to compare its performance. Filterability test of both membranes and their harvesting efficiency were conducted. Results show that nano fiber membrane is more hydrophilic (contact angle of zero), and has $45 \%$ higher surface pore size and $20 \%$ surface pore population that contribute significantly into its higher clean water permeability (of 1018 and 493 l/m2hbar for nano fiber and PVDF membranes respectively). From the filterability results, the nano fiber membrane has more advantages over the phase inverted one (2-5 times higher in productivity while maintaining similar rejection of 92\%).

Figure-2 shows the details of the experimental setup.

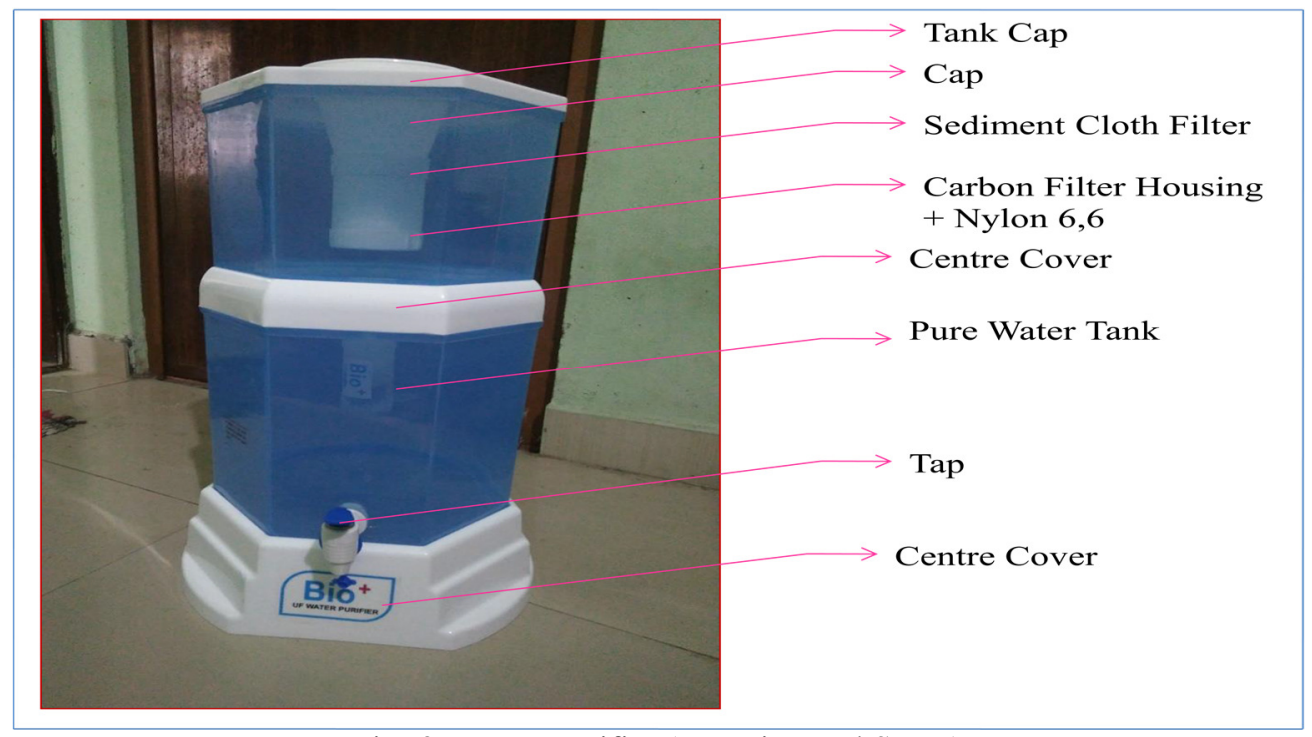

Fig.-2: Water Purifier (Experimental Setup)

\section{Silver Activated Carbon}

Silver Activated carbon is used to purify liquids and gases in a variety of applications, including municipal drinking water, food and beverage processing, odor removal, industrial pollution control, and point-of-use filters in the home. Also helps in killing bacteria, gas purification, gold purification, metal extraction, water purification, medicine, sewage treatment, air filters, decaffeination, pet litter and odor removal.

\section{Nylon 6,6}

Nylon comes from a family of synthetic polymers known as polyamide and was first introduced by Wallace Carothers on 28th February 1935. Nylon 6,6 is a polyamide made by polycondensation of adipic acid methylenediamine, and contains a total of 12 carbon atoms in each repeating unit and make polyamides suitable for plastic applications are resistance to toughness, thermal stability, good appearance, resistance to chemicals etc.

\section{Sediment Cloth Filter}

A sediment filter acts as a sieve to remove these particles and don't remove chemicals or heavy metals or make the water taste or smell better. Sediment filters can be made of a variety of materials are used to 
make the sediment filters and the most common are wound string or cord, polypropylene, polyester, cellulose, ceramic, glass fiber, and cotton.

\section{Water flow rate}

The Fig.-3 illustrates that water flow rate of nylon membrane of pore size 0.45 micron is more as compared to the pore size 0.2 micron. Pressure drop of pore size 0.2 micron i.e $3.52 \mathrm{~kg} / \mathrm{cm}^{2}$ is more than the pressure drop of pore size 0.45 micron i.e. $2.25 \mathrm{~kg} / \mathrm{cm}^{2}$. The rate of filtration of water purifier is very less, it takes more time to filter the water and remove a high amount of E.coli from the groundwater sample i.e. bore well water, tap water and pond water which is passed through a nylon membrane

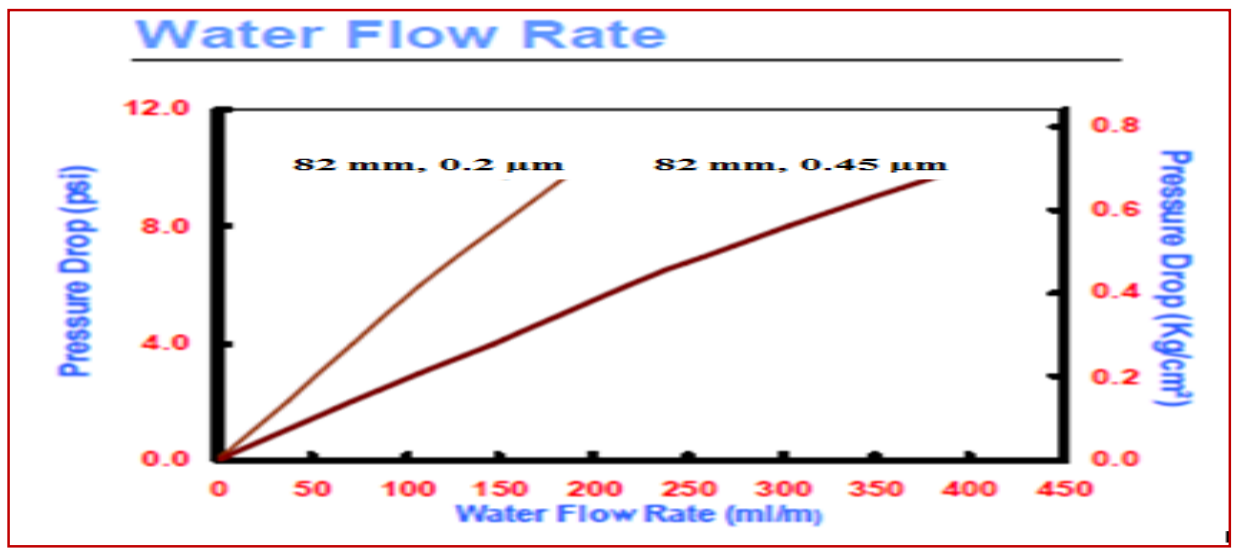

\section{Procedure}

Fig.-3: Water Flow Rate

Set up a water purifier (named Bio filters) and arranged a 1/2 filter in between the filter mechanisms of the filter machine. Checked its efficiency by passing water be it tap water, bore well water and pond water. The filtered water was checked in the lab for the E.Coli concentration.Pressure drop of nylon membrane of pore size 0.2 micron and 0.45 micron is $3.52 \mathrm{~kg} / \mathrm{cm}^{2}, 2.25 \mathrm{~kg} / \mathrm{cm}^{2}$ respectively.

\section{E.Coli Bacterial Analysis Method}

Viable Count Method or Colony Forming Count (CFC) methods are used to measure E.Coli bacteria. Viable count method can be accomplished by techniques such as pour plating, spread plating, and most probable number method. Plate count assumes that every colony is founded by a single cell. Based on the known volume of culture/sample that was spread on plate and colonies are counted and the E.Coli concentration has been calculated. Prior to plating, samples are heavily diluted in order to obtain single colonies.
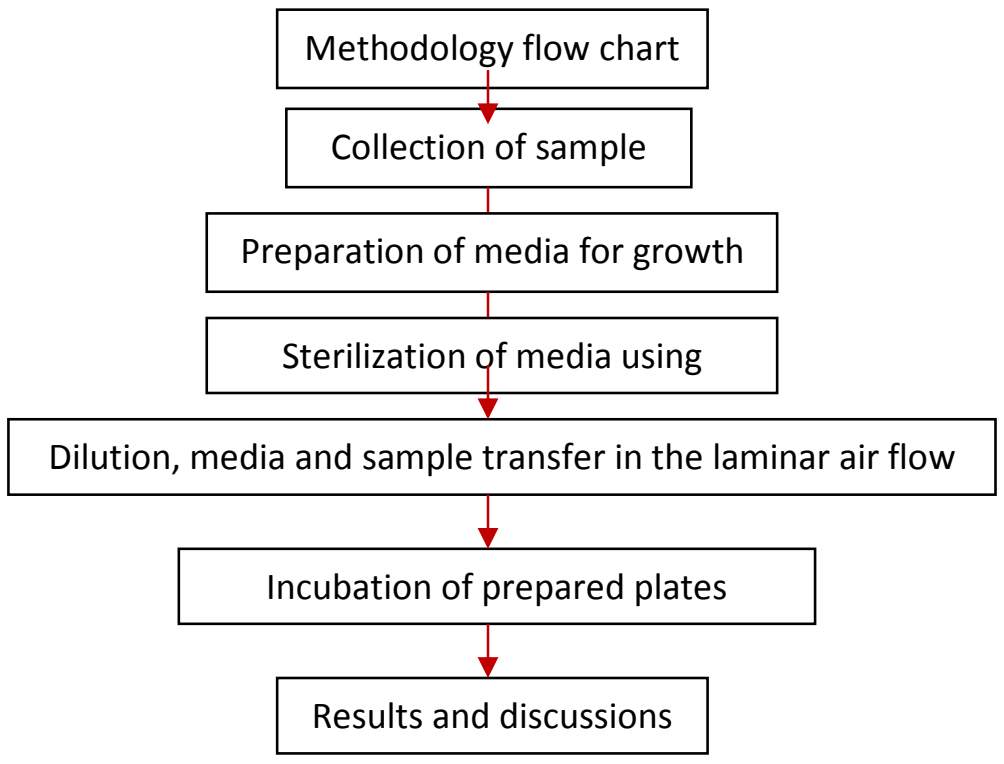


\section{Collection of Sample}

Sample collected from tap water Fig.-4a, bore water Fig.-4b and from pond water Fig.-4c $n$ the closed container with minimum air inside it. Refrigerate these samples to prevent the growth of microbes inside the sample. Do not store the sample for more than one day.

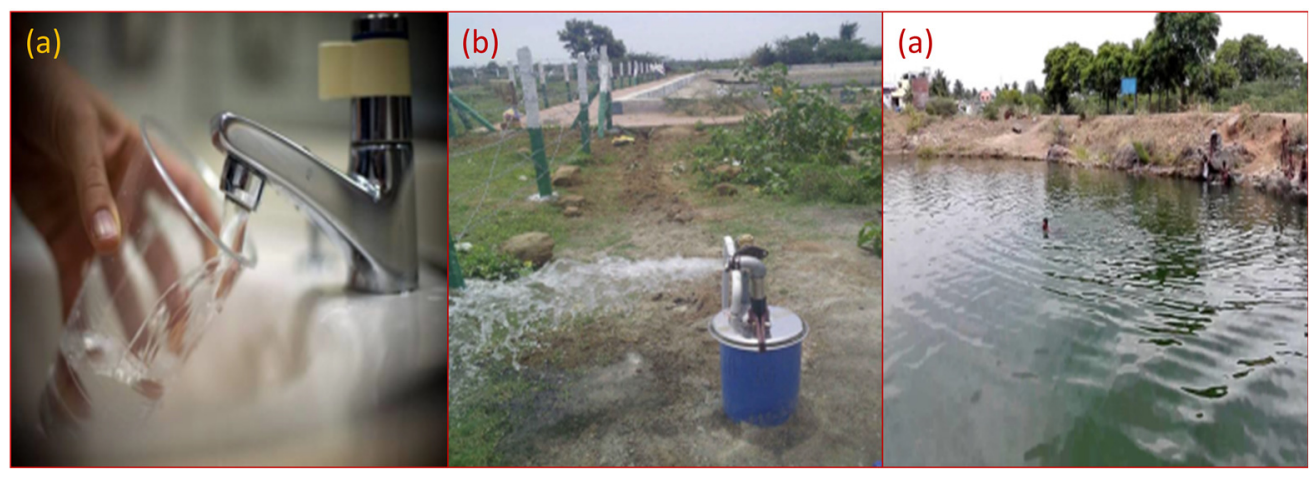

Fig.-4:(a) Tap Water (b) Bore Well Water (c) Pond Water

\section{Preparation of Media for Bacterial Growth}

Apparatus required for preparation of media for bacterial growth is $100 \mathrm{~mL}$ media, $250 \mathrm{ml}$ conical flask, 2 gm of Luria Broth(LB),4gm Nutrient Agar , $100 \mathrm{ml}$ distilled water, water bath, etc. Procedure: Take 100 $\mathrm{ml}$ distilled water in $250 \mathrm{ml}$ clean conical flask. And take $2 \mathrm{gm}$ of Luria broth on glossy paper. As Luria broth is hygroscopic, transfer the measured quantity immediately in the conical flask. Shake well until it dissolves completely in water. Transfer measured $2 \mathrm{gm}$ of Nutrient Agar in the above solution. Heat the flask on a water bath $\left(80-90^{\circ} \mathrm{C}\right)$ until agar dissolves completely. (Even if some lumps are remaining then they will get dissolved in an autoclave). Seal the flask with a cotton plug and cover it with the paper before placing it in an autoclave.

\section{Sterilization of Media Using Autoclave}

Apparatus required for sterilization of media is Autoclave instrument (OSWORLD LTD.) Fig.-5a. Set the autoclave to at $121^{\circ} \mathrm{C}$, time 15 minute, pressure $15 \mathrm{lbs} / \mathrm{cm}^{2}$. Cover everything to be placed in an autoclave with paper. Check the water level in the autoclave (water level must be just above to cover the perforated plate in the autoclave). Do not put glassware with water on the outside surface of it. Tighten the lid of the autoclave with the provided screws on the lid. Tight the two opposite screws at a time and the steam release knob on the lid. After checking the settings, turn on the autoclave. It will take about $1 \mathrm{hr}$ to reach the desired temperature. When the temperature reaches $121^{\circ} \mathrm{C}$, the countdown will start. After the end of the cycle, wait until the temperature of autoclave reaches $80-85^{\circ} \mathrm{C}$, then open the lid. For that first release the steam valve, then open the opposite screws with help of metal rod. Remove the apparatus inside the autoclave using gloves. Pour the media in Petri plates immediately only inside Laminar Air Flow Chamber after autoclave, otherwise medium will get solidified inside the flask. And the sterile apparatus from autoclave should be opened inside the laminar air flow chamber only.

\section{Laminar Air flow Chamber}

Figure-5b shows Laminar Chamber and it consists of a closed chamber with two burners, laminar air flow, UV light and the door which slides up and down vertically. The dilutions, sample transfer, pouring media into petri plates demand sterile conditions. Laminar air flow chamber provides those conditions. About $15 \mathrm{~cm}$ diameter sphere around the burner flame is more sterile. So dilutions, transfer of media and sample, spreading are done in the area between two burners.

Turn on the light and fan of the Laminar Air Flow Chamber. Clean the hands and laminar with $70 \%$ ethanol in water using cotton (the area between two burners should be cleaned properly) Light two burners. Any operation such as transfer of material should be done in between two burners only. Open the Petri plates from autoclave in such a way to minimize air exposure. Open flask between two burners. Hold the neck of flask near the burner every time you open it. Pour the media in the Petri plates. The 
media should form a uniform layer inside the plate. Transfer the specific amount of the sample to the Petri plates and spread the sample using a spreader. Before spreading, the spreader should be sterilized by holding it on the burner flame. When the spreader cools then spreading should be done. After these steps, mark the plates according to the sample and do not open the lid of the plates otherwise contamination from the air will take place.
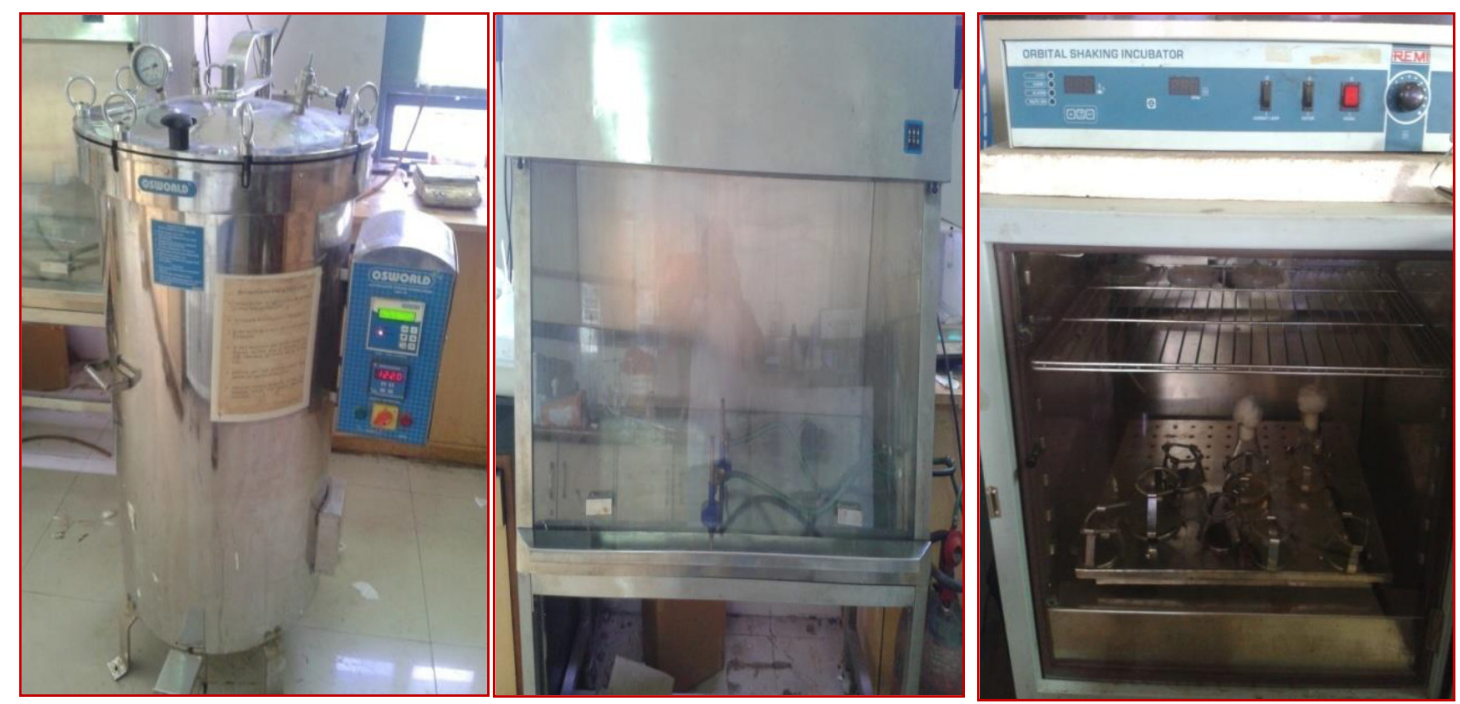

Fig.-5:(a) Autoclave Machine (b) Laminar Chamber (c) Shaking Incubator

\section{Incubation}

Figure-5c shows the shaking incubator. While lifting and placing the Petri plates, do not open the lid. Place each Petri plate separately inside the incubator. Set the temperature of the incubator as per the requirement. Let the petri plates remain inside the incubator for minimum 24 hours.

\section{Preparation of $E$.Coli culture}

Take $100 \mathrm{ml}$ of distilled water and add $2.5 \mathrm{~g}$ of Nutrient Broth (NB) in $250 \mathrm{ml}$ conical flask (conical flask should be clean and dry). Shake well so that NB gets dissolved properly and heat if necessary. Cover the mouth of the conical flask with cotton and then with paper Use rubber band to tighten the plug. Place the conical flask solution in Autoclave (Autoclave at temperature $121^{\circ} \mathrm{C}$, the pressure of $15 \mathrm{lb} / \mathrm{cm}^{2}$, and time 15 minute). After the Autoclave cycle is complete, remove the conical flask from it and allow it to cool down at room temperature only in Laminar Chamber. Before using laminar air flow Chamber, it should be cleaned with $70 \%$ ethanol solution. Properly dip the Loop and shake it to E.Coli culture, and then dip the E.Coli containing Loop to conical flask solution and shake it properly. Place the Conical flask solution to Incubator at $37^{\circ} \mathrm{C}$ and $120 \mathrm{RPM}$. Leave it for at least 12 hours to 16 hours so that fresh E.Colican grows in it. After 16 hours the solution has become turbid which indicates that the E.Coli has growth has taken place.

\section{Sub Culturing of E.Coli}

Take $100 \mathrm{ml}$ of distilled water and add $2.5 \mathrm{~g}$ of Luria Broth(LB), $3 \mathrm{~g}$ of Agar-Agar Type-I in $250 \mathrm{ml}$ conical flask (conical flask should be clean and dry). Shake well so that Luria Broth and Agar get dissolved properly and heat if necessary. Cover the mouth of the conical flask with cotton and then with paper. Use a rubber band to tighten the plug. Place the conical flask solution in Autoclave (Autoclave at temperature $121^{\circ} \mathrm{C}$, the pressure of $15 \mathrm{lb} / \mathrm{cm}^{2}$, and time 15 minute). After the Autoclave cycle is complete, remove the conical flask from it and allow it to cool down at room temperature only in Laminar Chamber. Before using laminar air flow Chamber, it should be cleaned with $70 \%$ ethanol solution. Then pour the solution to 4 test tubes and 2 Petri plates in Laminar Chamber only and allow it to cool for approximately 1 hour. Properly dip the Loop to E.Coli liquid culture, and then spread the E.Coli containing Loop to the surface of solidified Agar plates and test tubes. Place the Conical flask solution to 
RASĀYAN J. Chem.

Vol. 12 | No. 1 |32 - 39| January - March | 2019

Incubator at $37^{\circ} \mathrm{C}$ and $120 \mathrm{RPM}$. Leave it for at least 12 hours to 16 hours so that fresh E.Coli can grow in it. After 16 hours, the Petri plates and test tubes have shown whitish growth on its surface which indicates that the E.Coli has growth has taken place. Table 3 illustrates the initial concentrations of E.coli spiked in bore well water, tap water and bore well water with targeted bacteria before treatment expressed in an average count of $\mathrm{cfu} / \mathrm{ml}$.

Table-4:E.Coli Concentration in bore well water, Tap water, and Pond Water sources before and after treatment

\begin{tabular}{c|c|c|c}
\hline \multirow{2}{*}{ Water source } & $\begin{array}{c}\text { E.Coli } \text { concentrations }(\mathrm{cfu} / \mathrm{ml}) \text { before } \\
\text { filtration }\end{array}$ & \multicolumn{2}{|c}{ E.Coli concentrations (cfu/ml) after filtration } \\
\cline { 3 - 4 } & $4 \times 106$ & 1 Filter Used & 2 Filter Used \\
\hline Bore well water & $7 \times 106$ & $1 \times 106$ & 0 \\
\hline Tap water & $137 \times 106$ & $1 \times 106$ & 0 \\
\hline Pond water & & $74 \times 106$ & $30 \times 106$ \\
\hline
\end{tabular}
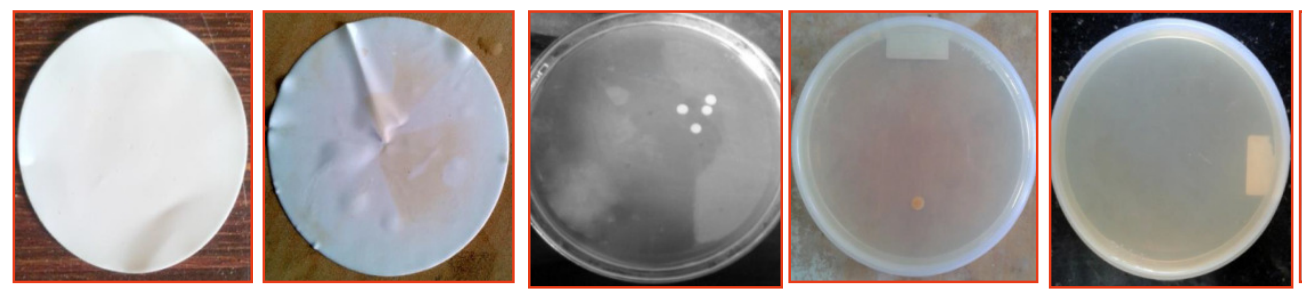

Fig.-6:Bore Well - (1) Nylon Membrane before filtration, (2) Nylon Membrane after filtration, (3) Sample without filtration, (4) Sample with 1 filter Used, (5) Sample with 2 filters Used, (6) Control sample
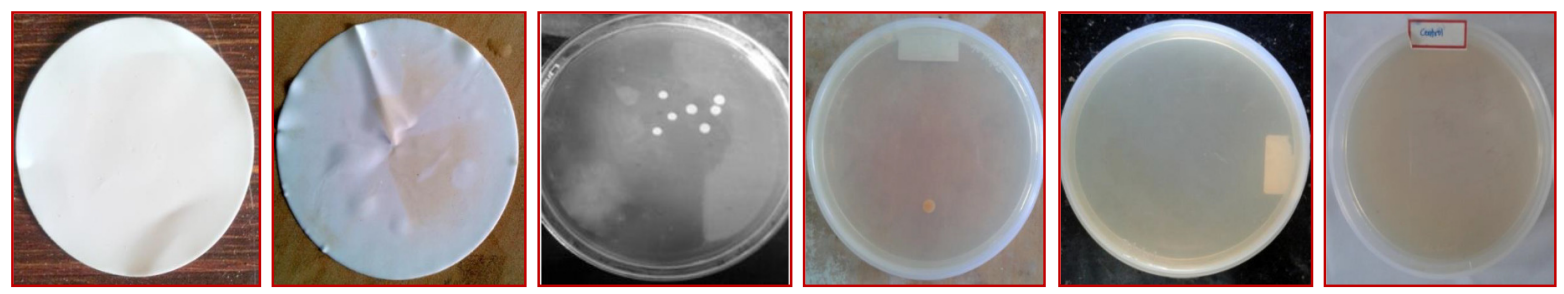

Fig.-7:Tape Water - (1) Nylon Membrane before filtration, (2) Nylon Membrane after filtration, (3) Sample without filtration, (4) Sample with 1 filter Used, (5) Sample with 2 filters Used, (6) Control sample
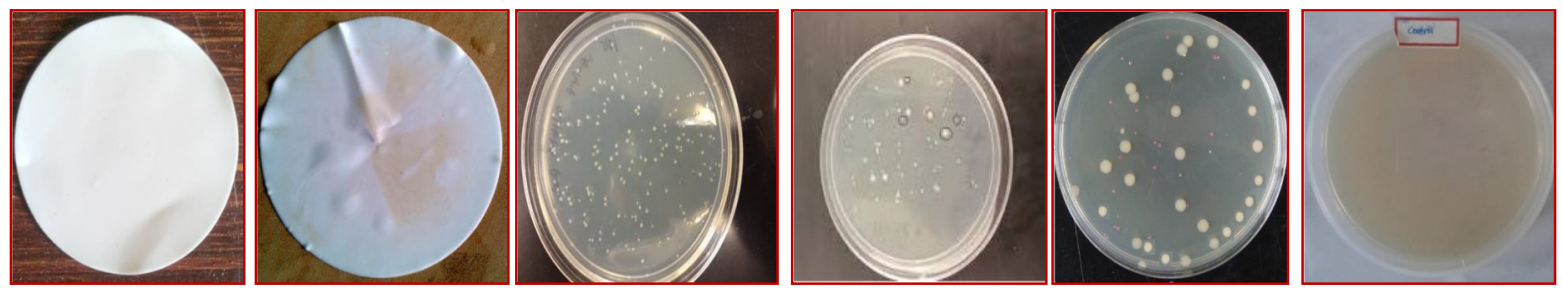

Fig.-8: Pond Water - (1) Nylon Membrane before filtration, (2) Nylon Membrane after filtration, (3) Sample without filtration, (4) Sample with 1 filter Used, (5) Sample with 2 filters Used, (6) Control sample

Developing countries have made de-centralized systems vital for the development of new technologies, especially in scattered communities depending on total nylon groundwater supplies. The study explored the use of nylon membrane which is cost-effective materials locally available for use in drinking groundwater disinfection.

\section{CONCLUSION}

The filtration system was used to improve the purity of the groundwater sample. Nylon membrane was tested for antibacterial activity and showed excellent antibacterial filtration performance against E. coli. Number of E.Coli was detected in the output water, based on the performance of the membrane as an antibacterial water filter system. The single membrane is not so good systems for the disinfection of drinking water because of low bacterial removal. A combined membrane system is the sole drinkingwater purification system suggested. Complete anti-microbial solutions to rural communities can be an 
RASĀYAN J. Chem.

Vol. 12 | No. 1 |32 - 39| January - March | 2019

offer by this technology. Future studies will be conducted on the coating of the nylon filter system with some cheap available antibacterial agent.

\section{REFERENCES}

1. Jocelyne K. Mwabi, Bhekie B. Mamba and Maggy N. B. Momba, Int. J. Environ. Res. Public Health, 9, 139(2013), DOI: 10.3390/ijerph9010139

2. WHO, Guidelines for drinking-water quality, edition IV, ISBN 978-92-4-154995-0 (2017).

3. Jocelyne K. Mwabi, Bhekie B. Mamba and Maggy N. B. Momba, Water SA, 39(4), 445(2013),

4. S. Murcott, Proc. Electronic Conference Hosted by USAID/ Hygiene Improvement Project (HIP), 12(22), 1-39(2006).

5. M.R. Adams and M.O. Moss, The Royal Society of Chemistry, Cambridge, U.K, 8(5), 2-5 (1995).

6. Duson Kimmer, Radka Korinkova and Lubomirkubac, Institute of Botany of the ascr, Brno, Czech Republic, EU, 17(4), 4-8 (2012).

7. Jocelyne K. Mwabi, Bhekie B. Mamba and Maggy N. B. Momba, Int. J. Environ. Res. Public Health, 9(1), 139(2012), DOI: 10.3390/ijerph9010139.

8. Maggy N. B. Momba, Jocelyne K. Mwabi, Maggy N.B. Momba, B. M. Brouckaert, C. Swartz, G. Offringa and R.O. Rugimbane, WRC Report (2013).

9. Flor Yazmín Ramírez-Castillo, Abraham Loera-Muro, Mario Jacques, Philippe Garneau, Francisco Javier Avelar-González, Josée Harel and Alma Lilián Guerrero-Barrera, 4, 307(2015), DOI:10.3390/pathogens4020307.

10. Aola Supong, Parimal Chandra Bhomick, Dipak Sinha, MOJ Toxicol, 3(6), 146 (2017).

11. Deepshikha Garg, Rajdeep Kaur, Dinesh Chand, Satish Kumar Mehla and R.V. Singh, Rasayan J. Chem., 1(4), 743(2008).

12. A. Suresh, K. Ramesh Babu, Swarna Latha and A. V. V. Swamy, Rasayan J. Chem., 9(2), 222(2016).

13. Deepak Kumar, Vinay Kumar and Sangeeta Kumari, Rasayan J. Chem.,11(4), 1477(2018), DOI: 10.31788/RJC.2018.1143075,

14. Kosovo Nexhdet Shala, Ibrahim Hoxha, Gafur Q. Xhabiri and Bajram Avdiu, Rasayan J. Chem., 11(4), 1399(2018), DOI: 10.31788/RJC.2018.1144065.

15. N. Karikalan, Rasayan J.Chem., 11(4), 1451(2018), DOI: 10.31788/RJC.2018.1143068.

[RJC-5041/2018] 